\title{
Inhibitory Effects of Several Fluoroquinolones on Feline CYP1A and $3 A$ in Hepatic Microsomes
}

\author{
Syed Sher Shah Sadaat ${ }^{*}$, Nasrin Stankzi², Mohammad Monir Tawfeeq1, Farid Ahmad Tanin ${ }^{1}$, \\ Amanullah Aziz ${ }^{1}$, Kazuki Sasaki ${ }^{3}$ \\ ${ }^{1}$ Department of Clinic, Faculty of Veterinary Science, Kabul University, Kabul, Afghanistan \\ ${ }^{2}$ Department of Pre Clinic, Faculty of Veterinary Science, Kabul University, Kabul, Afghanistan \\ ${ }^{3}$ Department of Veterinary Medicine, Faculty of Agriculture, Tokyo University of Agriculture and Technology, Tokyo, Japan \\ Email: *sadaat@ku.edu.af
}

How to cite this paper: Sadaat, S.S.S., Stankzi, N., Tawfeeq, Md.M., Tanin, F.A., Aziz, A. and Sasaki, K. (2020) Inhibitory Effects of Several Fluoroquinolones on Feline CYP1A and 3A in Hepatic Microsomes Open Journal of Veterinary Medicine, 10, 219-237.

https://doi.org/10.4236/ojvm.2020.1012019

Received: November 24, 2020

Accepted: December 28, 2020

Published: December 31, 2020

Copyright $\odot 2020$ by author(s) and Scientific Research Publishing Inc. This work is licensed under the Creative Commons Attribution International License (CC BY 4.0).

http://creativecommons.org/licenses/by/4.0/

\begin{abstract}
In this study, the effects of several fluoroquinolones (FQs), such as Ciprofloxacin (CPFX); Orbifloxacin (OBFX); Norfloxacin (NFX); Ofloxacin (OFX); and Enerofloxacin (EFX) on activities of both Cytochrome P450 1A (CYP1A) and Cytochrome P450 3A (CYP3A) of feline microsomes by in vitro tests were studied. Ethoxyresorufin O-deethylation (EROD) and Midazolam 1' hydroxylation and 4-hydroxylation (MDZ1'H and MDZ4H) were analyzed by High Performance Liquid Chromatography (HPLC). All the FQs inhibited the reactions by a competitive or noncompetitive and irreversible manner. The inhibitory constants $\left(\mathrm{K}_{\mathrm{i}}\right)$ were as followings: CYP1A; ranged from 0.12 to $1.23 \mathrm{mM}$ for NFX, OBFX, EFX, CPFX, OFX and CYP3A, for MDZ1'H; ranged from 5.8 to 35 and $\mathrm{MDZ} 4 \mathrm{H} ; 9$ to $29 \mathrm{mM}$, respectively. As these values are higher by 24 to 200 -times of given single clinical dose of serum levels after application of FQs. It indicates that if co-administrated with these FQs by reversible inhibitory manner, the inhibition of CYP1A and CYP3A effect on CYP1A and 3A actions is not very significant to cause drug interaction with above mentioned enzyme substrates. Out of the FQs tested, CPFX and NFX for CYP1A, and CPFX for CYP3A showed irreversible inhibitory effects (time-dependent), so it has been concluded that these drugs may cause drug-drug interaction by accumulation, when they are repeatedly administrated. Since EFX is biotransformed to CPFX by the liver, it could have the identical risk too.
\end{abstract}

\section{Keywords}

Several Fluoroquinolones, CYP Inhibitors, EROD, Midazolam, Microsomes 


\section{Introduction}

Cytochrome P450s (CYPs) are the most significant enzymes of phase one drug biotransformation in the liver that is important for the removal of many drugs and xenobiotic. A patient response to drugs can be determined by action of these enzymes. Impairment of medication breakdown as a consequence of drug interaction, either by pharmacokinetic or pharmacodynamic; may result in some clinical complications such as harmfulness as a result of a high level plasma levels or reduced elimination. Among drug-drug interaction, there are many reports on increases in drug concentrations caused by inhibition of oxidative metabolism through CYPs. Therefore, much care has been taken for the factors that alter drug biotransformation. Modifications in drug biotransformation in general enzyme induction [1] or enzyme inhibition [2] can alter the drug biotransformation. Enzyme reserve course typically comprises competition through additional drug at enzyme binding site during concurrent drug administration. The course regularly initiates with the principal dose of the CYP inhibitors. Enzyme inhibition is well predictable as a basis of clinically substantial opposing drug interaction [3] [4], since the enzyme inhibition could foremost to fatal toxicity of co-administered drugs [5].

Subfamilies of CYP1A and CYP3A enzymes were inhibited by many drugs as a substrate. FQs antibiotics inhibited CYP1A and CYP3A activities [6] in humans [7] [8] and other different animal species like dogs [9], chickens and rats [10].

Fluoroquinolones are effective antimicrobial agents for treatment of variety of infections [11]. These agents are used in the treatment of several human and animals. Although, clinical experiences with these compounds have so far demonstrated them to be relatively safe and well-tolerated in most patients [12]. There are many reports available of interference with the metabolism of CYP1A and CYP3A in different species such as dogs by irreversible manner [13], human [14], and cats [15]. These interactions influence from FQs inhibitory effects on CYP1A, and CYP3A subfamilies. FQs-mediated inhibition of these enzymes prevents the metabolism/inactivation of methylxantines such as caffeine and theophylline [16]. The first report of impaired drug clearance by FQs appeared in 1984 [17]. Out of FQs, CPFX is the most potent inhibitor in humans as compared to NFX, OFX, Sarafloxacin (SPFX) and Levofloxacin (LFX) has negligible effect on CYP1A and CYP3A enzyme activities [16]. As CYP3A subfamily includes paramount important enzymes which metabolize more than $50 \%$ of all drugs therefore they are at high risk of both reversible and irreversible inhibition [18]. In addition, McLellan et al. (11) reported reversible competitive inhibitory effect of CPFX and NFX on EROD catalyzed by CYP1A in human and rat microsomes. Similarly, reversible competitive inhibitory effects of CPFX and NFX on THP metabolism catalyzed by CYP1A in rat liver microsomes also reported [18] [19] and [20]. A reversible and irreversible inhibitory effect of several FQs on hepatic microsomal CYP1A and CYP3A has been reported by Regmi et al. [9] in dogs. Furthermore Rando [17] then Palfreyman [21] described irreversible or else 
time-dependent inhibition. By understanding the inhibitory effects and potency of drugs we can better anticipate and manage enzyme inhibition in clinical condition.

The administration of FQs to felines and canines constitutes the largest application of these drugs in veterinary medicine. They have been used extensively during the past 20 years for the treatment of contagions of the dermal disease and many other systemic infections meanwhile having high efficacy, best delivery form and inclusive beneficial therapeutic index. Since the enzyme inhibition by FQs may cause clinically significant drug interaction, so having information about them is too essential for veterinary clinicians. Nevertheless, studies on inhibitory effects of FQs in feline patients are not available. Hence the main goal of current study was to find out inhibitory effects in feline species.

\section{Materials and Methods}

\subsection{Animals}

Four male and four female cats (short hair, 2 years old, 2.3 to $3.2 \mathrm{~kg}$ weight) have gotten from Iffa Credo (France). Each cat was housed separately in a stainless-steel cage with a 12 -h light/dark rotation. Household heat and virtual moisture were sustained at $18^{\circ} \mathrm{C}-22^{\circ} \mathrm{C}$ and $41 \%-71 \%$, in turn. The animals were feed (Science diet, feline care, Hill's pet Nourishment, Topeca, KS, USA) one time a day in addition permitted them admission to water access ad libitum. The animals were exposed to the trail after $24 \mathrm{~h}$ fast dated. The test procedure was in agreement with the procedures designed for the maintenance and usage of research laboratory animals, Faculty of Agriculture, Tokyo University of Agriculture and Technology.

\subsection{Medicines and Chemical Compounds}

Resorufin as substrate, 7-ethoxyresorufin, NFX, glucose-6-phosphate and glucose-6-phosphate dehydrogenase have been delivered by Sigma Chemical CO. Ltd (St Louis, MO, USA). OFX and OBFX have given by Daiich Seiyaku CO. Ltd (Tokyo, Japan) and Dainippon Pharmaceutical CO. Ltd (Osaka, Japan), in turn. CPFX and EFX remained from (Bayer Japan, Tokyo, Japan). Entirely compounds and substances stayed of investigative, organic or HPLC mark.

\subsection{Preparation of Feline Hepatic Microsomes}

Cats remained starve overnight, euthanized in anesthesia by way of i.v. bolus dose of pentobarbital sodium at an amount rate of $25 \mathrm{mg} / \mathrm{kg}$ (Nembutal; Dainippon Pharmaceutical CO. Ltd, Osaka, Japan), formerly the livers remained directly detached then retained into ice. Microsomal portions have been set as per defined earlier by Vaccaro [19] with a minor manipulation that using a commercially available dye reagent (Bio-Rad Protein Asssay ${ }^{\oplus}$, Bio-Rad Laboratories, INC., CA. U.S.A.). Arranged samples have reserved at $-80^{\circ} \mathrm{C}$ till used. Whole protein level and CYP content were resolute as demonstrated formerly by Bradford and Omura [18] [22] [23]. 


\subsection{Enzyme Assay}

EROD and Midazolam metabolites ( 1 ' and 4 hydroxylation) reactions have been used to regulate the kinetics of CYP1A and CYP3A actions in feline hepatic microsomes, separately. The responses progressed at $37^{\circ} \mathrm{C}$ in $50 \mathrm{mM}$ sodium/potassium phosphate buffer ( $\mathrm{pH}$ 7.4) comprising NADPH-generating system $(0.5 \mathrm{mM}$ ßNADP $^{+}, 5 \mathrm{mM}$ glucose-6-phosphate, $1.5 \mathrm{U} / \mathrm{ml}$ glucose-6-phosphate dehydrogenase, $5 \mathrm{mM} \mathrm{MgCl}_{2}$ ), and fairly accurate amount rate of $0.03 \mathrm{mg} / \mathrm{mL}$ microsomal protein in a volume of $1 \mathrm{ml}$ for EROD and $0.4 \mathrm{mg} / \mathrm{mL}$ for the two metabolites of midazolam (1' and 4 hydroxylation). There was 5 -min preincubation by $37^{\circ} \mathrm{C}$ in advance the reaction was progressed through adding the substrate by 0.1 normal acetic acid (solvent of FQ solution), or FQ solution. The meditations of ethoxyresorufin in the examine structure reached after 0.065 to $1.55 \mu \mathrm{M}$. Subsequently the incubation at $37^{\circ} \mathrm{C}$ aimed at $15 \mathrm{~min}$, the response has been reduced by totaling $3 \mathrm{~mL}$ of methanol then retained on ice aimed at $5 \mathrm{~min}$. Subsequently, centrifugation by $2000 \mathrm{~g}$ for $5 \mathrm{~min}, 1 \mathrm{~mL}$ of the resultant supernatant have been moved to a perfect test tube, and $4 \mathrm{~mL}$ of methanol was auxiliary to the examine structure [13]. The level of MDZ has been reached by $15-307 \mu \mathrm{M}$. Then nurtured at $37^{\circ} \mathrm{C}$ aimed at 10 minutes, the response has been stopped by addition of $250 \mu \mathrm{M}$ acetonitrile then placing in ice aimed at least 5 minutes. The content was centrifuged at $(10,000 \mathrm{~g}$ for a period of $2 \mathrm{~min})$ before the supernatant sieved by a $0.45 \mu \mathrm{M}$ filter. $50 \mu \mathrm{L}$ of attained filtrate has been abruptly examined to define the level of Midazolam metabolites ( 1 ' and 4 hydroxylation).

\subsection{Reversible Inhibition Experiments}

Firstly, FQs were thawed in $0.1 \mathrm{~N}$ acetic acid before $10 \mu \mathrm{L}$ of the solution added to the examine structure just earlier the adding of substrate. The level of FQs were $0.2 \mathrm{mg} / \mathrm{mL}(0.5-0.6 \mathrm{mM})$ and $0.5 \mathrm{mg} / \mathrm{mL}(2.0-2.5 \mathrm{mM})$, based on the molecular weights of FQs in the examined structure for EROD and Midazolam metabolites (1' and 4 hydroxylation), separately [18]. The data after collection was analyzed by Lineweaver-Burk double reciprocal schemes to govern the method of inhibition (competitive or noncompetitive).

\subsection{Time-Dependent Inhibition Experiments}

The examined structure has been primed after a preincubation of $5 \mathrm{~min}$, before every FQ added then incubated for 0,5 , and 10 or 15 minutes, the substrate has supplemented on a concentration of $1.04 \mu \mathrm{M}$ for EROD. The meditation of FQs remained $0.2 \mathrm{mg} / \mathrm{mL}$. In the examined structure of CYP3A the preincubation was $5 \mathrm{~min}$, after every FQs were supplemented, then raised for periods of 0,10 , 20 or $30 \mathrm{~min}$, the intended substrate has been supplemented at a meditation of $123 \mu \mathrm{M}$ used for Midazolam metabolites ( 1 ' and 4 hydroxylation) in the examined structure. The application of FQs was $0.8 \mathrm{mg} / \mathrm{mL}$ in the examined structure. The application of every FQs in the examined structure has been similar to those illustrated in the reversible inhibition trial [9]. 


\subsection{Determination of Resorufin}

Resorufin concentration in the combination calculated by a fluorometric technique as defined earlier [24] [25] with a spectrofluorometric technique (RF-1500; Shimadzu Corporation, Kyoto, Japan). The fluorescence has been monitored at $550 \mathrm{~nm}$ of excitation wavelength and $586 \mathrm{~nm}$ of emission wavelength. The discovery border has been $0.05 \mathrm{nM}$ on a signal-to-noise proportion of 3 . The repossession ratio of Resorufin remained $102 \% \pm 5 \%$ (Coefficient of Variance, $5.7 \%)$ at $20 \mathrm{nM}(\mathrm{n}=4)$. The intra-day CVs were 3.9 and $5.2 \%$ at 20 and $400 \mathrm{nM}$ $(\mathrm{n}=4)$, separately. The inter-day CVs were reached $3.3-6.2 \mathrm{nM}$ and $1.5 \%$ $5.2 \%$ at 20 and $400 \mathrm{nM}$, separately (For a period of three days, 4 purposes in a day). The verified FQs did not disturb the Resorufin examined structure.

\subsection{Determination of Midazolam Metabolites (1' and 4 Hydroxylation)}

Midazolam metabolites (1' and 4 hydroxylation) have been resulted by a reversed level HPLC through UV-discovery as shown by Kuroha et al. [26]. A $\mathrm{C}_{18}$ (TSK-gel $^{\oplus}$; ODS-120T, $5 \mu$ m element mass, $250 \times$ 4.6-mm i.d, Tosoh CO., Tokyo, Japan) column has been used to investigate data. The Support effluence has checked by $254 \mathrm{~nm}$ wavelengths with a UV-sensor (SPD-6A, Shimadzu Corporation, Kyoto, Japan). The portable level is combined by $100 \mathrm{mM}$ acetate buffer $(\mathrm{pH} 4.7)$, acetonitrile and methanol (58.9:34:5.5, v/v/v). The current proportion of the mobile level has been set $1 \mathrm{~mL} / \mathrm{min}$. The discovery borders were $3.5 \mathrm{ng} / \mathrm{mL}$ for $\mathrm{MDZ} 4 \mathrm{H}$ and $2.4 \mathrm{ng} / \mathrm{ml}$ for MDZ1'H, separately, on a signal-to-noise proportion of 3. The repossession of MDZ1'H was $102 \% \pm 1.3 \%$ by Coefficient of Variations $(1.3 \%)$ at $1 \mu \mathrm{g} / \mathrm{mL}(\mathrm{n}=4)$. The intra-day CVs were $1.3 \%$ and $5.3 \%$ by 0.1 and $1 \mu \mathrm{g} / \mathrm{mL}$, separately $(\mathrm{n}=4)$. The inter-day CVs were reached $1.3 \%-2.5 \%$ then $2.2 \%-5.6 \%$ at 0.1 and $1 \mu \mathrm{g} / \mathrm{mL}$, separately (three days, 4 -determinations/day). The repossession of $\mathrm{MDZ} 4 \mathrm{H}$ was $103 \pm 3.3 \%(\mathrm{CV}=2.5 \%)$ at $1 \mu \mathrm{g} / \mathrm{mL}(\mathrm{n}=4)$. The intra-day CVs were 1.1 and $3.8 \%$ next to 0.1 then $1 \mu \mathrm{g} / \mathrm{mL}$, separately $(\mathrm{n}=$ 4). The inter-day CVs reached $0.3 \%-0.4 \%$ then $2.5 \%-8.6 \%$ by 0.1 then 1 $\mu \mathrm{g} / \mathrm{mL}$, separately (three days, 4-purposes in a day).

\subsection{Enzyme Kinetic Study}

A double reciprocal Lineweaver-Burk scheme designated a competitive mode of inhibition for NRX, OBFX, ERX, and OFX but CPFX showed noncompetitive, the bellow calculations were used to study the enzyme kinetics of EROD without or with FQs, Equations (1) \& (2) used to analyze competitive inhibition and Equations (3) \& (4) in noncompetitive inhibition.

$$
\begin{gathered}
v=\frac{V_{\max } \times S}{K_{m}+S} \\
v=\frac{V_{\max } \times S}{K_{m} \times\left(1+\frac{I}{K_{I}}\right)+S}
\end{gathered}
$$




$$
v=\frac{V_{\max } \times S}{\left(K_{m}+S\right)\left(1+\frac{I}{K_{i}}\right)}
$$

MDZ1' hydroxylation showed uncompetitive substrate inhibition, consisted with Mechaelis-Menten kinetics as demonstrated by Kuroha et al. [2], then the succeeding equations have fitted to MDZ1' hydroxylation kinetics without or with FQs studied.

$$
v=\frac{V_{\max } \times S}{\left(1+\frac{I}{K_{i}}\right)\left(K_{m}+S\left(1+\frac{S}{K_{s}}\right)\right)}
$$

In the above equation, $V_{\max }$ shows maximal velocity and $K_{m}$ indicates Mechaelis-Menten constant. Where, $S$ indicates meditations of the substrate and $I$ indicating inhibitors. Dissociation constant of inhibitors is shown by $K_{\dot{r}}$. Two reactions velocity substrate application curves for every FQs concurrently examined. A software MULTI package is used to examine the statistics [27] to attain the kinetic comprising $V_{\max }, K_{m}$ and $K_{i}$.

\subsection{Statistics}

The differences was calculated by using paired $t$-test and considered significant when $\mathrm{p}$ value was less than 0.05. A Graph pad prism version 7.03 for window software. La (Inc., Chicago, IL, Jolla California, USA) was used.

\section{Results}

\subsection{Reversible Inhibition}

Demonstrative Lineweaver-Burk schemes showed that all FQs has inhibited the enzyme response by a competitive mode, but CPFX by a noncompetitive (Figure 1). EROD reaction was inhibited by all FQs in cats' hepatic microsomes as shown in (Figure 2). The reaction followed normal single-enzyme Mechaelis-Menten kinetics; apparent Mechaelis-Menten kinetic parameters $V_{\max }, k_{m}$ and $K_{i}$ values are shown in (Table 1).

The schemes of the response velocities contrary to substrate meditations using or lack of FQs have been concurrently studied by a nonlinear least squares suitable package, with equalities (1) and (2) for competitive and equalities (1) and (3) for noncompetitive inhibition to estimate $K_{i}$ standards. Theoretical appearances has fixed fine by the experimental values (Figure 2). Of the FQs investigated in this study, NFX showed the lowest $K_{i}$ value, showing its inhibitory outcome was the utmost strong amongst the five FQs, have been observed in this study. The value, nevertheless, was rather bigger $(0.12 \mathrm{mM})$. Instead, FQs showed about 2, 5, 6, and 10-times values intended for OBFX, EFX, CPFX and OFX, individually comparable with NFX. It is therefore, reversible inhibition might not effect in a drug interaction with added drugs that are substrates intended for CYP1A enzyme. 
Table 1. Apparent Mechaelis-Menten kinetic parameters of EROD and inhibitory constants of fluoroquinolones in hepatic microsomes of cats.

\begin{tabular}{ccccc}
\hline Fluoroquinolones & $\begin{array}{c}V_{\max } \\
(\mathrm{nmol} / \mathrm{min} / \mathrm{mg} \\
\text { protein) }\end{array}$ & $\begin{array}{c}K_{m} \\
(\mu \mathrm{M})\end{array}$ & $\begin{array}{c}V_{\max } / K_{m} \\
(\mathrm{nmol} / \mathrm{min} / \mathrm{mg} \\
\text { protein })\end{array}$ & $\begin{array}{c}K_{i} \\
(\mathrm{mM})\end{array}$ \\
\hline NFX & $0.22 \pm 0.10$ & $0.22 \pm 0.06$ & $1.07 \pm 0.65$ & $0.12 \pm 0.05$ \\
OBFX & $0.33 \pm 0.11$ & $0.29 \pm 0.08$ & $1.18 \pm 0.43$ & $0.25 \pm 0.06$ \\
EFX & $0.23 \pm 0.09$ & $0.17 \pm 0.02$ & $1.32 \pm 0.42$ & $0.59 \pm 0.23$ \\
CPFX & $0.29 \pm 0.08$ & $0.16 \pm 0.03$ & $1.86 \pm 0.40$ & $0.74 \pm 0.20$ \\
OFX & $0.23 \pm 0.09$ & $0.17 \pm 0.03$ & $1.39 \pm 0.69$ & $1.23 \pm 0.63$ \\
\hline
\end{tabular}

Every assessment has denoted by mean $\pm S D(n=4)$. Every FQs, dual response velocity-substrate concentration curves has been concurrently studied by nonlinear least squares fitting program to evaluate the kinetic parameters comprising $V_{\max }, K_{m}$ and $K_{\dot{p}}$ NFX, Norfloxacin; OBXF, Orbifloxacin; EFX, Enerofloxacin; CPFX, Ciprofloxacin; OFX, Ofloxacin.
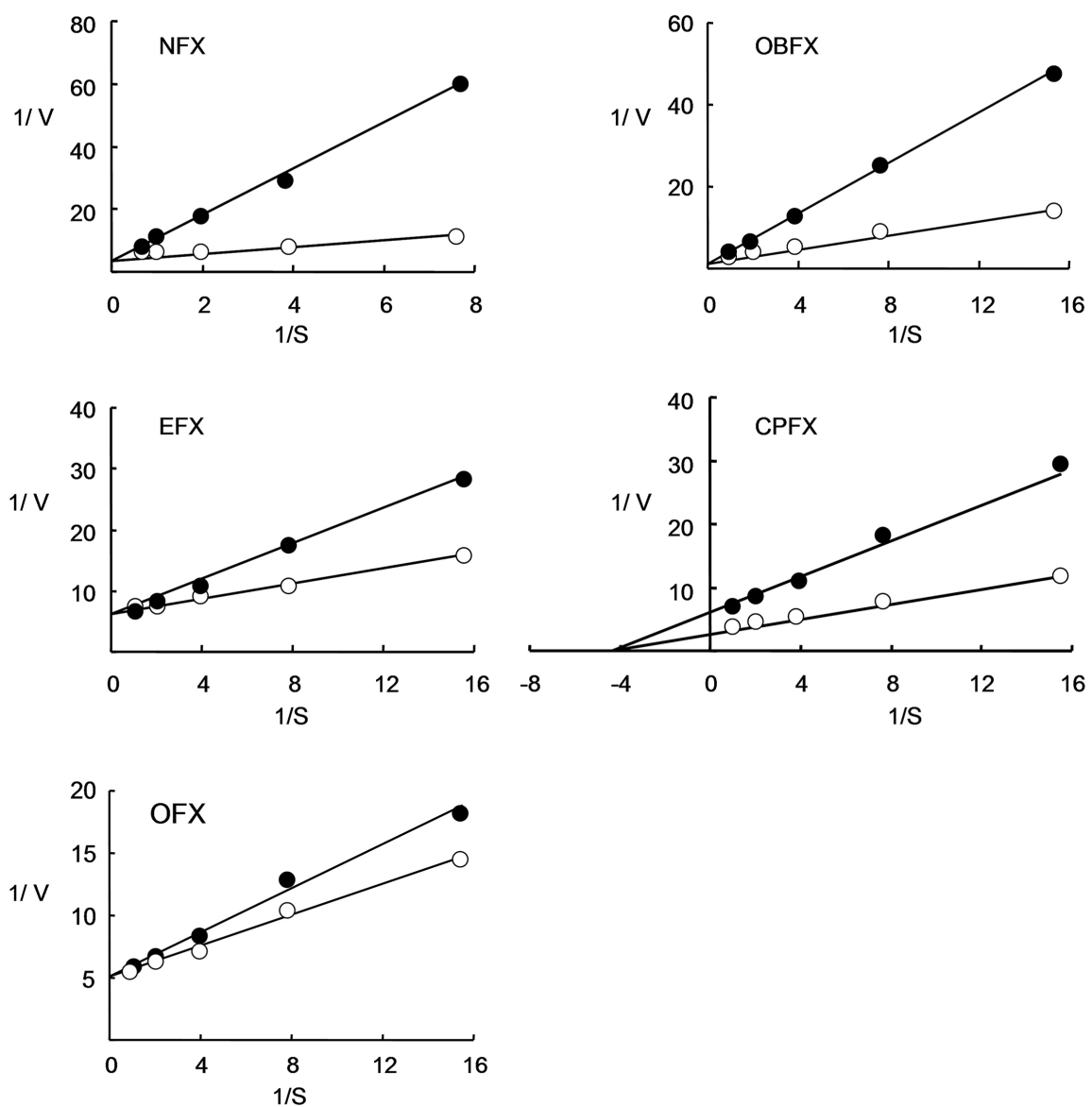

Figure 1. Representative Lineweaver-Burk scheme of EROD degrees contrary to substrate concentrations. Reaction velocity points are with FQs (sealed spheres) or without FQs (exposed spheres). In these plots microsomes from four male cats were used. NFX, Norfloxacin; OBFX, Orbifloxacin; EFX. Enerofloxacin; CPFX, Ciprofloxacin; and OFX, Ofloxacin; $\mathrm{S}$, Shows the concentrations of substrate in $\mu \mathrm{M} ; \mathrm{V}$, shows reaction rates of EROD in $\mathrm{nmol} / \mathrm{min} / \mathrm{mg}$ protein. 

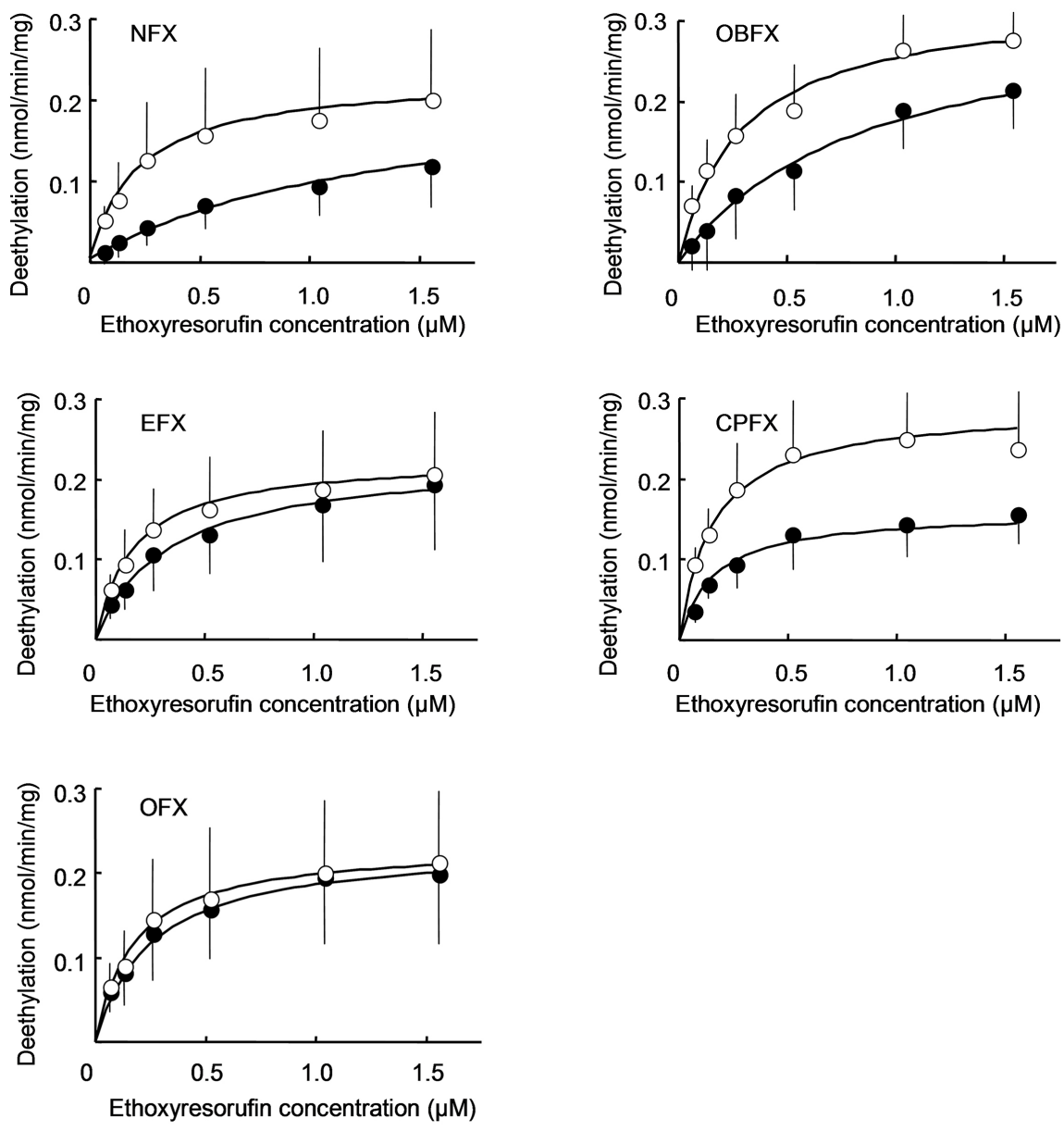

Figure 2. Michaels-Menten kinetics profile of EROD in presence or absence of FQs. The vertical bars and points represent mean \pm SD as of four male cat's hepatic microsomes. Exposed spheres obtained from responses in absence fluoroquinolones (vehicle addition). Sealed spheres were obtained from reactions with FQs at $0.2 \mathrm{mg} / \mathrm{mL}$. The solid curves in the figure have been calculated by Equation (1), (2) and (3) as illustrated in material and methods unit by kinetic considerations in Table 1 .

The representative of Lineweaver-Burk schemes for the inhibitory effect on MDZ4-hydroxylation has been demonstrated in (Figure 3). The schemes has designated that several FQs inhibited enzyme reactions by means of a noncompetitive mode in cats hepatic microsomes. The schemes of the response velocities contrary to substrate meditations using or lacking several FQs have been concurrently examined by a nonlinear least squares appropriately, with equalities 1 and 2 for MDZ4-hydroxylation and equalities 3 and 4 for MDZ1'-hydroxylation to estimate $K_{i}$. The intended appearances fixed fine per the experimental values (Figure 4 and Figure 5), showing the reliability of the analysis.

Mechaelis-Menten kinetic parameters, comprising $V_{\max }, K_{m}$ and $K_{i}$ are summarized in Table 2. The results in Table 2 demonstrated that CPFX taken a lowest $K_{i}$ value, representing its inhibitory outcome was the utmost effective amongst the drugs observed in this study. However, FQs had about 2, 4, 5 and 6-fold values of OBFX, NFX, OFX, EFX, respectively comparable with CPFX on 

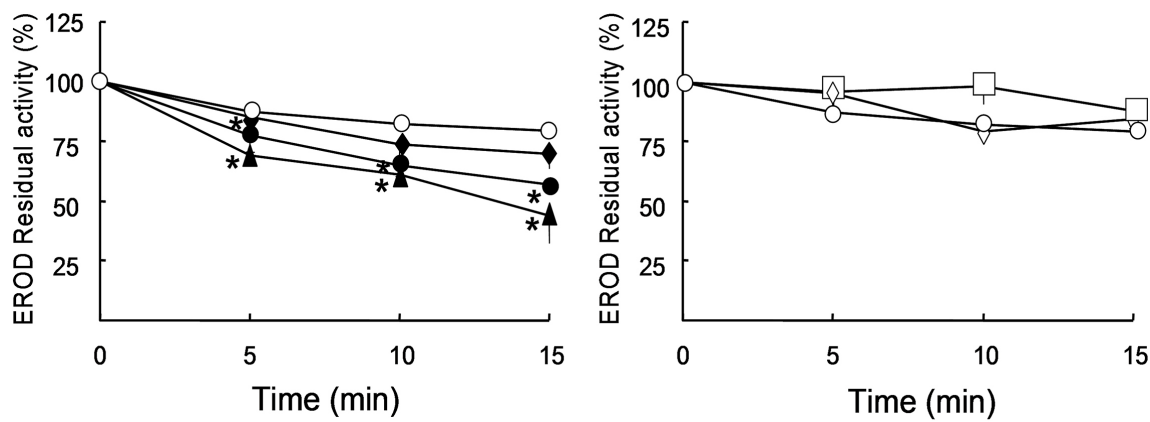

Figure 3. Demonstrated time-dependent enzyme inhibitory effects of FQs at 0, 5, 10 and 15 min after adding FQs. Every pillar characterizes shown by mean \pm SD from hepatic microsomes of four male cats. (०) represents vehicle, $(\bullet)$ represents effects of OFX, $(\bullet)$ represents effects of CPFX, $(\boldsymbol{\Delta})$ represents effects of NFX, $(\diamond)$ represents effects of OBFX and ( $\square$ ) represents effects of EFX. OFX, Ofloxacin; CPFX, ciprofloxacin; NFX, Norfloxacin; OBFX, Orbifloxacin; and EFX, Enerofloxacin. Concentrations of fluoroquinolones were $0.2 \mathrm{mg} / \mathrm{mL}$ and concentration of Resorufin was $1.04 \mu \mathrm{M}$. In the figure $\left(^{*}\right)$ indicate significant differences from reactions immediately after adding fluoroquinolones when $\mathrm{P}<0.05$.
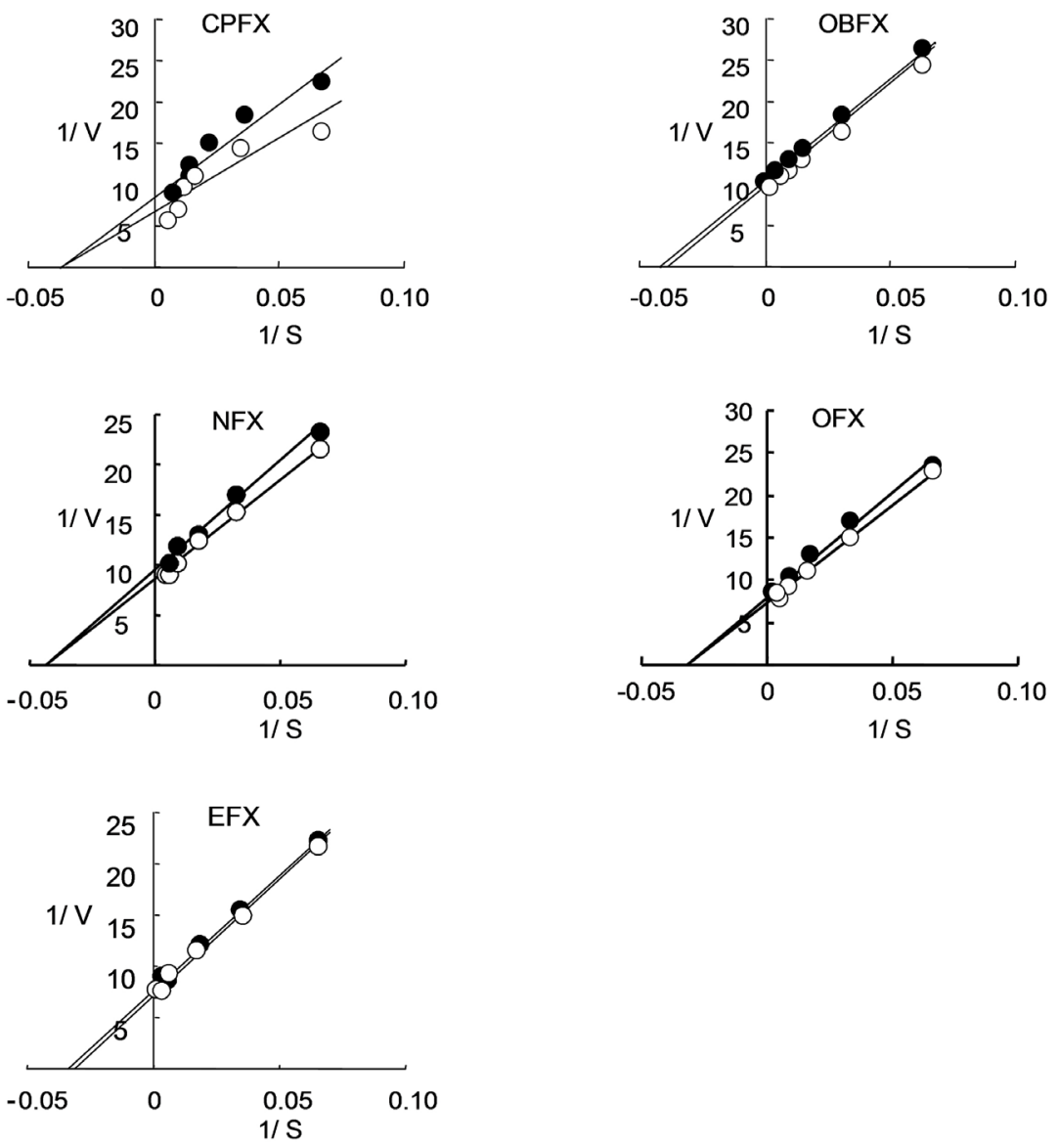

Figure 4. Shown Lineweaver-Burk scheme of MDZ4-hydroxylation rates against substrate concentrations. Reaction velocity points are with fluoroquinolones (sealed spheres) or without fluoroquinolones (exposed spheres). In this plots microsomes from four female cats were used. CPFX, ciprofloxacin; OBFX, Orbifloxacin; NFX; Norfloxacin; OFX, Ofloxacin; and EFX, Enerofloxacin. S, shown substrate concentrations in $\mu \mathrm{M} ; \mathrm{V}$, shown reaction degree of $\mathrm{MDZ} 4 \mathrm{H}$ in $\mathrm{nmol} / \mathrm{min} / \mathrm{mg}$ protein. 

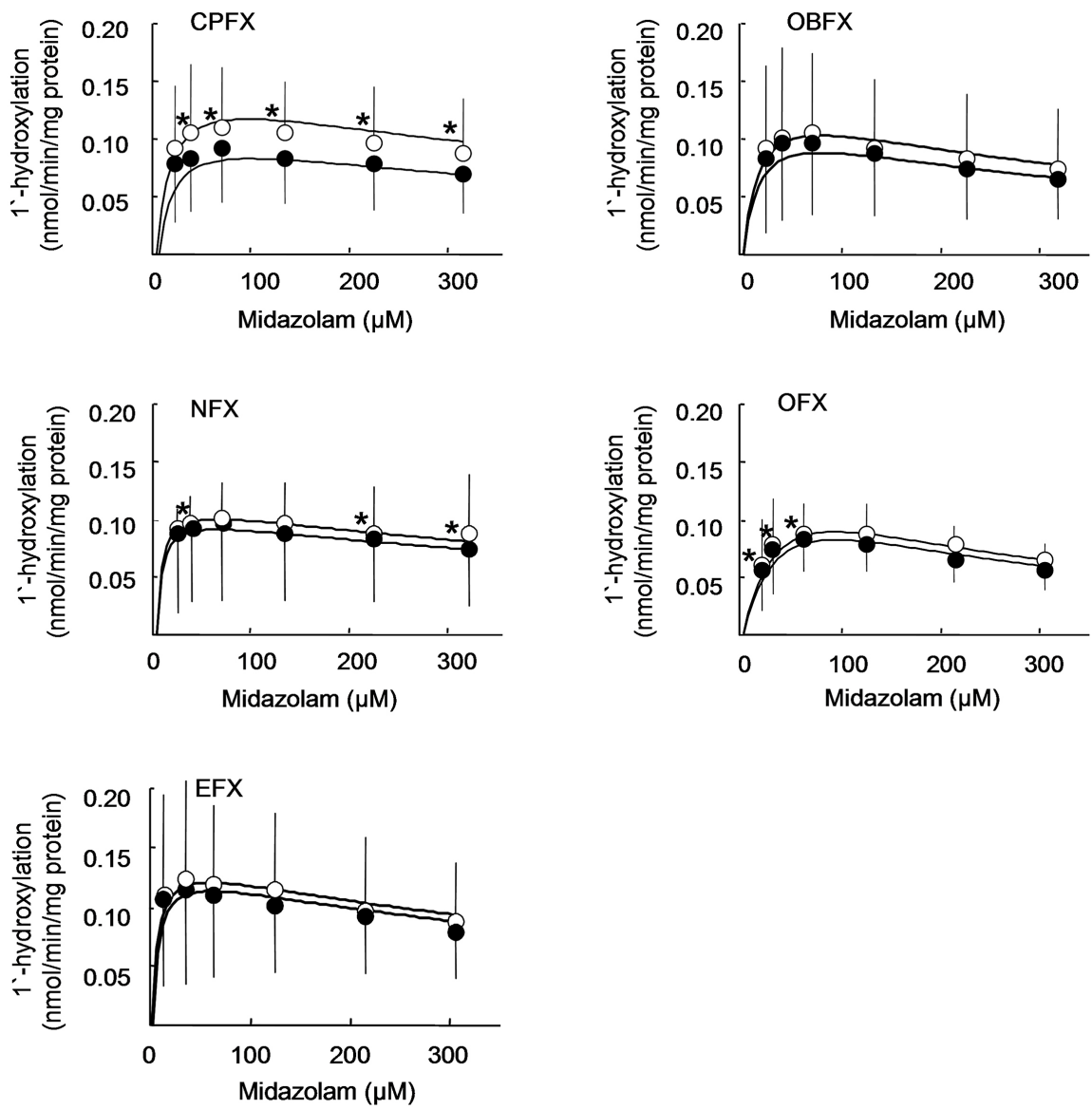

Figure 5. Mechaelis-Menten kinetics of 1'-hydroxylation of midazolam (MDZ1'H) with or without fluoroquinolones. Point and vertical line characterizes mean \pm SD of four female cats' hepatic microsomes. Exposed spheres depict reaction in absence of FQs (control). Sealed spheres have been obtained from the reactions in the presence of FQs at 2.0 $2.5 \mathrm{mM}$ in the evaluate size. MDZ concentration remained 15 to $307 \mu \mathrm{M}$ in the test. Solid curves in the figure have been achieved using Equations (3), (4) of Materials and Methods by using kinetic data of Table 2 . The significant differences have been shown by stars between reaction at the absence of FQs (control) and the reactions at the presence of FQs when $\mathrm{P}<0.05$

Table 2. Michaelis-Menten kinetic strictures for MDZ1'-hydroxylation and 4-hydroxylation with or without several FQs as CYP3A activity inhibiting hepatic microsomes from cats.

\begin{tabular}{ccccccc}
\hline \multirow{2}{*}{ Inhibitors } & \multicolumn{3}{c}{ 1'-hydroxymidazolam } & \multicolumn{3}{c}{ 4-hydroxymidazolam } \\
\cline { 2 - 7 } & $V_{\max }(\mathrm{nmol} / \mathrm{min} / \mathrm{kg})$ & $K_{m}(\mathrm{mM})$ & $K_{i}(\mathrm{mM})$ & $V_{\max }(\mathrm{nmol} / \mathrm{min} / \mathrm{kg})$ & $K_{m}(\mathrm{mM})$ & $K_{i}(\mathrm{mM})$ \\
\hline CPFX & $0.15 \pm 0.06$ & $14.62 \pm 13.24$ & $5.81 \pm 5.48$ & $0.15 \pm 0.07$ & $32.36 \pm 16.86$ & $9.13 \pm 2.23$ \\
OBFX & $0.14 \pm 0.08$ & $15.76 \pm 19.4$ & $11.68 \pm 3.45$ & $0.11 \pm 0.05$ & $29.29 \pm 10.45$ & $21.11 \pm 11.92$ \\
NFX & $0.12 \pm 0.07$ & $5.07 \pm 3.90$ & $25.60 \pm 12.94$ & $0.13 \pm 0.06$ & $29.11 \pm 14.01$ & $24.11 \pm 13.95$ \\
OFX & $0.17 \pm 0.06$ & $43.78 \pm 50.76$ & $32.98 \pm 20.40$ & $0.15 \pm 0.08$ & $39.43 \pm 17.22$ & $23.05 \pm 7.24$ \\
EFX & $0.14 \pm 0.08$ & $6.04 \pm 6.27$ & $34.68 \pm 31.49$ & $0.14 \pm 0.09$ & $29.88 \pm 4.26$ & $28.76 \pm 14.67$ \\
\hline
\end{tabular}

Every rate have been denoted by mean \pm SD $(n=4)$. Intended for every drug, two response velocity-substrate concentration curvatures have been instantaneously analyzed by means of a nonlinear least squares suitable package to approximate the kinetic stricture standards comprising $V_{\max }, K_{m}$ and $K_{\dot{p}}$ NFX, Norfloxacin; ORBFX, Orbifloxacin; EFX, Enerofloxacin; CPFX, ciprofloxacin; OFX, Ofloxacin. 
MDZ1'H. while FQs had about 2, 2.5, 2.6 and 3-folds values of OBFX, OFX, NFX and EFX, respectively comparable with CPFX on MDZ4 hydroxylation. It is therefore, the inhibitory effect by reversible mode could not result in a drug interaction by extra drugs, as a substrate for CYP3A. Nevertheless, the extent of inhibition on MDZ1'-hydroxylation and 4-hydroxylation were quite different. The mean $K_{i}$ values of FQs were relatively large and in the milimolar range. Results showed that effect of FQs on MDZ1'-hydroxylation and MDZ4-hydroxylation by reversible inhibition might not cause drug interaction with extra drugs, those are substrates for CYP3A enzyme.

\subsection{Irreversible Inhibition}

Figure 6 demonstrated the effect of time-exposure of FQs on EROD actions.
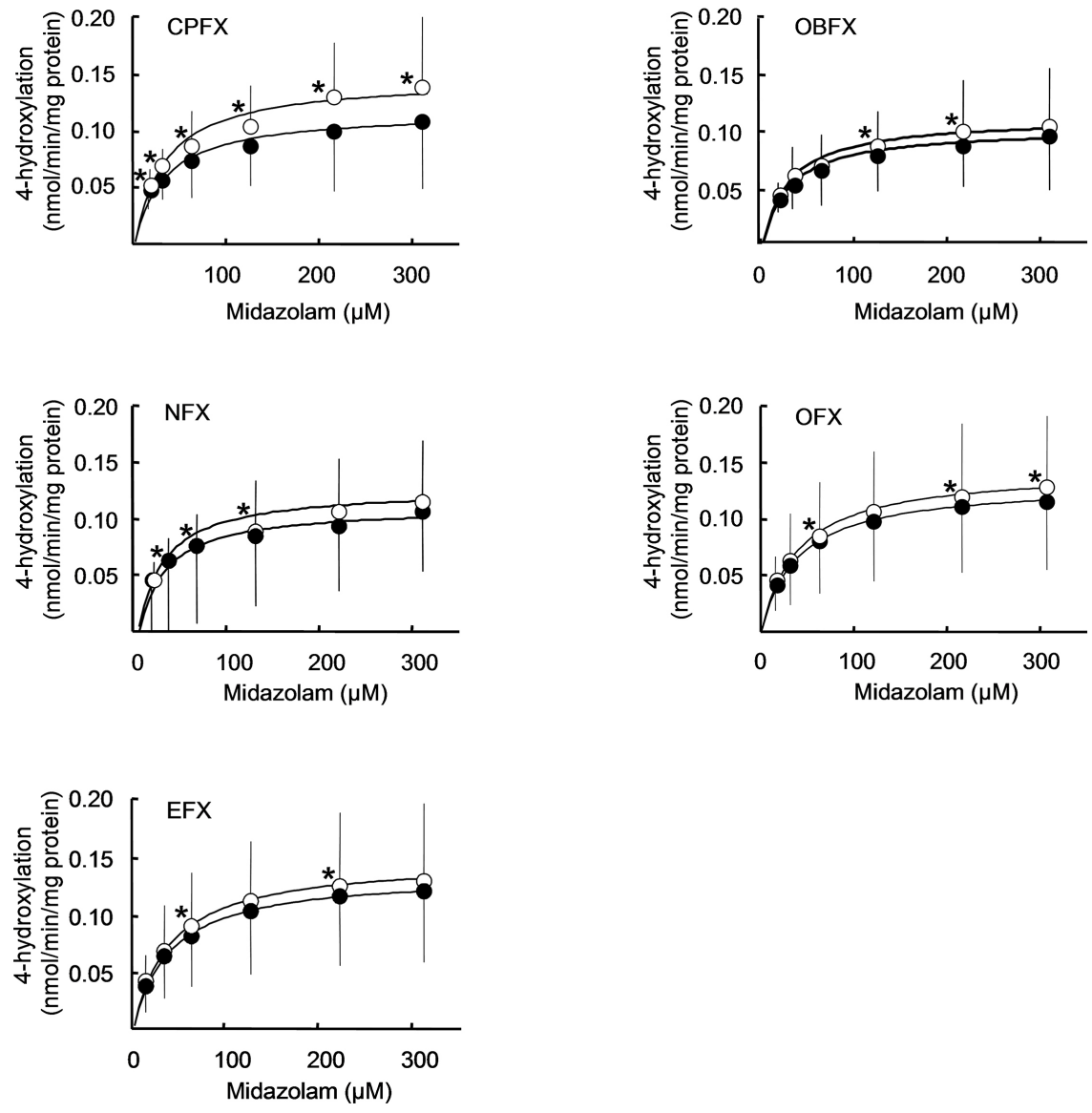

Figure 6. Mechaelis-Menten kinetics of 4-hydroxylation of midazolam (MDZ4-H) at the presence or absence of FQs. Each point and vertical line have represented by mean \pm SD of four female cats' hepatic microsomes. Reaction at the absence of FQs has shown by exposed spheres (control). While sealed spheres have been obtained from the reactions in presence of FQs at $2.0-2.5 \mathrm{mM}$ in the test. MDZ concentration remained 15 to $307 \mu \mathrm{M}$ in the assay system. Equations (1), (2) in Materials and Methods section using kinetic parameters in Table 2 were used to obtain hard curves in the figure. Significant difference between reaction in the absence of FQs (control) and the reactions in the presence of FQs has been shown by stars when $\mathrm{P}<0.05$. 
The two FQs, NFX and CPFX the reaction has decreased significantly, indicating that NFX and CPFX have inhibited the enzyme by time-dependent inhibition mode (irreversible mode). While ORBFX, OFX and EFX no any decrease has been observed. As per EFX biotransformed to CPFX in liver, it might has the same prospect.

Figure 7 and Figure 8 show the effects of exposure time of several FQs on MDZ1'-hydroxylation- and MDZ4-hydroxylation. As per CPFX, reactions has decreased meaningfully, indicating that CPFX inhibited the enzyme reactions by an irreversible manner (time-dependent inhibition).
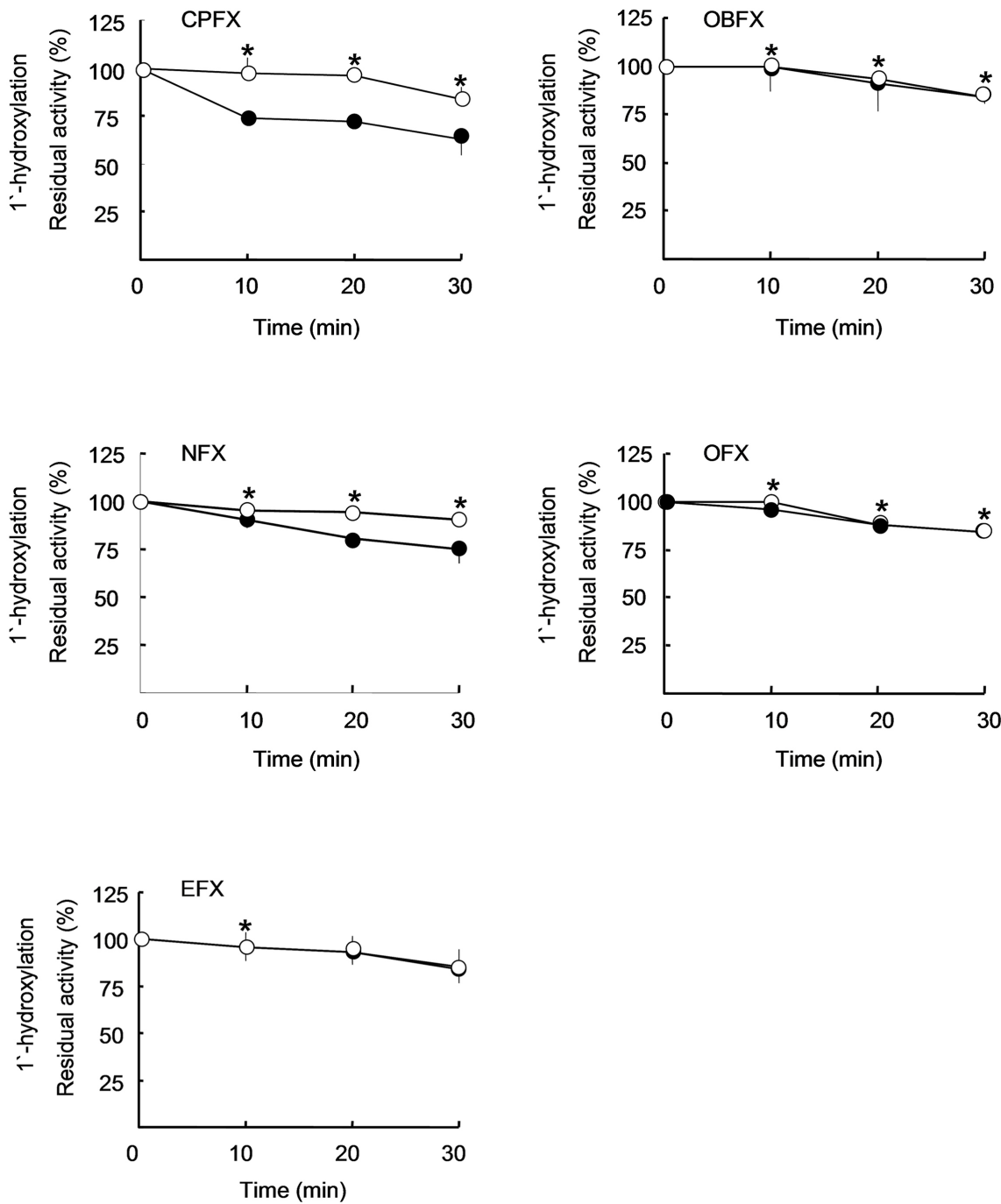

Figure 7. Time-dependent enzyme inhibition of fluoroquinolones at 0, 10, 20 and $30 \mathrm{~min}$ after adding FQs. Each point and vertical line represents mean \pm SD from four female cats' microsomes. Exposed spheres represent reaction without fluoroquinolones (control). Sealed spheres were obtained from the responses with FQs at $2.0-2.5 \mathrm{mM}$ in the examined volume. The meditation of MDZ remained $122 \mu \mathrm{M}$ in the examined structure. The inhibitory strength has been illustrated as percentage of catalytical action with FQs. Significant difference amongst reaction in absence of FQs (control) and the reactions with FQs have been shown by stars when $\mathrm{P}<0.05$. 

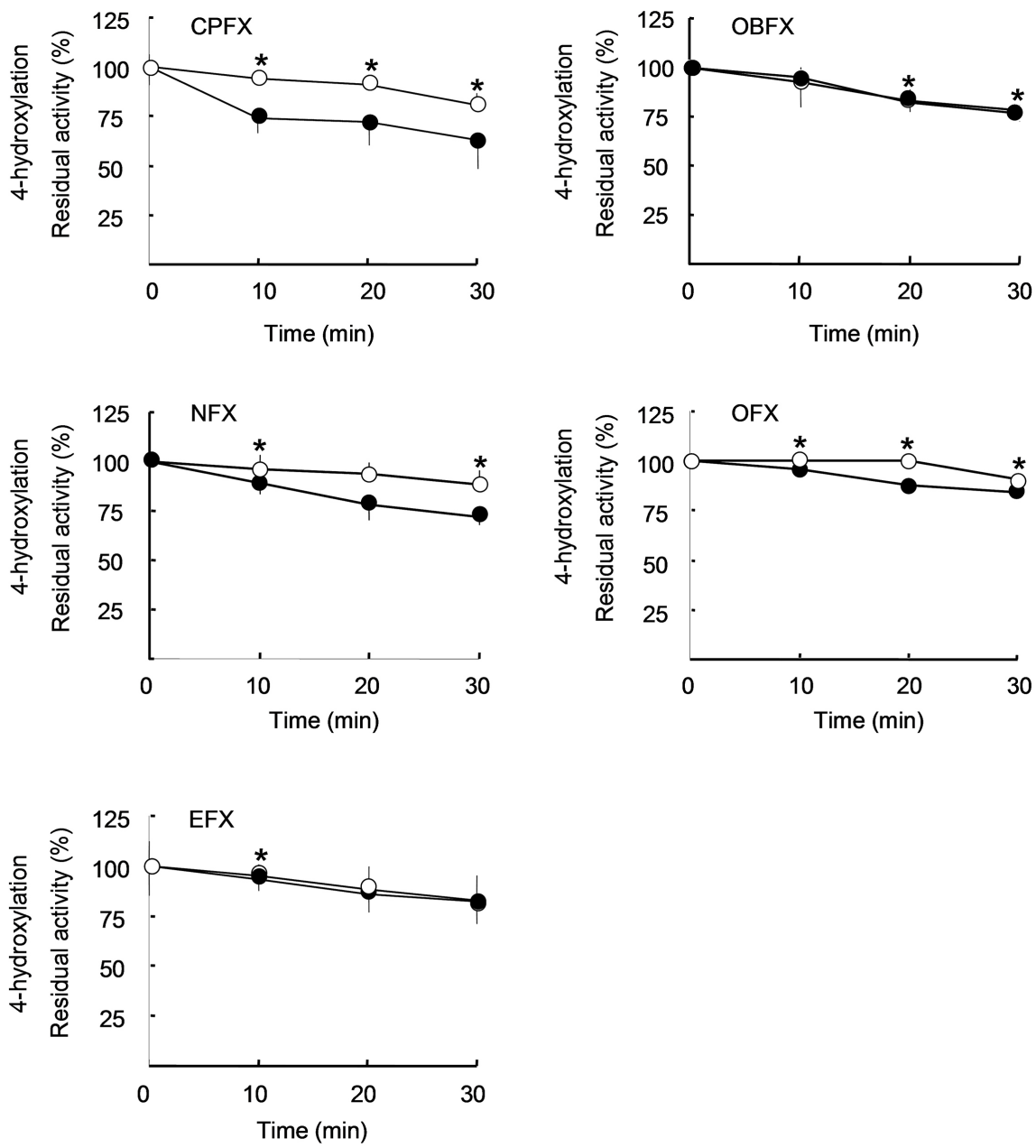

Figure 8. Irreversible enzyme inhibition of FQs at 0, 10, 20 and 30 min after adding FQs. Each point and vertical line represents mean \pm SD from four female cats' hepatic microsomes. Exposed spheres denote reaction in absence of FQs (control). Sealed spheres were obtained from the responses by FQs at $2.0-2.5 \mathrm{mM}$ in the examined volume. The meditation of MDZ remained $122 \mu \mathrm{M}$ in the examined structure. The inhibitory strength has been stressed in measurement of catalytical action with FQs. Significant difference amongst reaction in absence of FQs (control) and the reactions with FQs have been shown by stars when $\mathrm{P}<0.05$.

\section{Discussion}

The inhibitory effects of several FQs (NFX, OBFX, EFX, CPFX, and OFX) on EROD, MDZ1'-hydroxylation and MDZ4-hydroxylation reactions catalyzed by CYP1A besides CYP3A cat's hepatic microsomes were evaluated. The results showed that all FQs inhibited CYP1A activity by a competitive manner except CPFX which inhibited the enzyme activity in a noncompetitive mode, where the inhibitory mode on MDZ1'H and MDZ4H reactions for CYP3A activity by a noncompetitive manner in cats. The noncompetitive mode for OFX, OBFX, CPFX, EFX and NFX has been reported [13], although competitive inhibitory mode has been reported for CPFX and NFX in other animal species [10].

The obtained $K_{i}$ values were relatively large and in the milimolar ranged (0.12 
- $1.23 \mathrm{mM}$ ). However, the $K_{i}$ values for several FQs on CYP1A showed smaller values for NFX (1/40), OBFX (1/26), EFX (1/7), and OFX (1/8) compared to those of dogs [13]. In the case of CPFX, the $K_{i}$ value was almost similar to that of dogs [28]. These observations may suggest that the inhibitory effect of FQs on CYP1A activity was stronger in cats compared to that of dogs.

Of the FQs evaluated in this study (NFX, OBFX, EFX, CPFX and OFX), only EFX, OBFX and OFX are approved in Japan for cats. The recommended doses for cats have been reported to be $5 \mathrm{mg} / \mathrm{kg}$ in a day EFX, $2.5-5 \mathrm{mg} / \mathrm{kg}$ in a day OBFX then $5-10 \mathrm{mg} / \mathrm{kg}$ in a day OFX, separately. While for the EFX and OBFX routine doses could result in $C_{\max }$ of $<2 \mathrm{mg} / \mathrm{mL}(0.005 \mathrm{mM})$ at maximum, built on their pharmacokinetics subsequently via oral as a solitary dose in cats as reported by Rednic et al. [14] for EFX and OBFX, Dainippon Seiyaku (Osaka, Japan). In the case of OFX, pharmacokinetics study is not available in cats. However, the data from dogs may be referred, because the pharmacological effects depend on the drug concentrations. The $C_{\max }$ of OFX was reported to be 2.74 $\mu \mathrm{g} / \mathrm{mL}$ [28]. The $\mathrm{K}_{\mathrm{i}}$ values for OBFX, EFX and OFX were more than 24 to 200-folds higher than their $C_{\max }$ in plasma after oral administration at clinical dose. This suggests that these FQs possess extremely low inhibitory effects on CYP1A activities in cats. NFX and CPFX are not approved for cats in Japan and many other countries. Therefore, we cannot refer therapeutic doses of these antimicrobials in cats. If $5-10 \mathrm{mg} / \mathrm{kg} /$ day are used for these drugs as a therapeutic dose, $C_{\max }$ may be less than $2 \mu \mathrm{g} / \mathrm{mL}$. While, Albarellos et al. [29] reported $C_{\max }$ of CPFX $1.26 \mu \mathrm{g} / \mathrm{mL}(0.004 \mathrm{mM})$. Although pharmacokinetic study is not available for NFX in cats, that in dog is reported by Regemi et al. [9]. In this study, $C_{\max }$ was $0.177 \mu \mathrm{g} / \mathrm{mL}(0.0005 \mathrm{mM})$. It is therefore, $K_{i}$ values of NFX and CPFX may be 200-folds higher than $C_{\max }$. This suggests that inhibitory effects of FQs on CYP1A activities are extremely low in reversible inhibition manner. Hence the effect of inhibition might not result in drug interaction during multi-drug therapy in cats by this mode. Even if $K_{i}$ values of FQs might be usually too large to produce considerable inhibition on CYP1A actions in clinical state, human's studies for some FQs confirmed inhibition of CYP1A1/2 by in vivo tests by beneficial doses. Cutting-edge in human it has been reported orally concurrent therapy of EFX, CPFX, PFX and OFX caused in 74.0\% [30], 30.4\% ([31], 29.4\% and $12 \%$ [32] reduction in entire body clearance of THP, separately. Similar drug-drug interaction between EFX and THP is also reported in human [33]. As well, in dogs it has been reported that stable state meditations of THP after multiple i.v. bolus of EFX, although there was no accumulation of this drug but plasma concentrations of EFX has been increased [34]. Since $K_{i}$ values of these FQs are quite large in these animal species, these remarks propose alternative inhibition mechanism of FQs on CYP1A actions. It is therefore, the possibility of irreversible inhibitory effects of the FQs on CYP1A actions has been also investigated in this study on hepatic microsomes of cats.

As shown in Figure 3, NFX and CPFX inhibited CYP1A activities in an irre- 
versible manner. These results show that the above FQs inhibited CYP1A activities by a time-dependent inhibition in cats. Whereas this inhibition is irreversible, it is therefore may result in significant inhibitory effects even in clinical conditions. These drugs may cause drug-drug interaction by accumulation, when they are repeatedly administrated. Since ENFX is biotransformed to CPFX by the liver, it could also have the identical risk. A similar irreversible inhibition CYP1A activity is reported by Regmi et al. [13] in dogs.

It is well known that ENFX, CPFX, OFX, ORBFX, and NFX inhibit CYP1A activities in dogs. Regmi et al. [13] confirmed that the abovementioned FQs could inhibit EROD in a non-competitive manner in hepatic microsomes attained from dogs. While in our study we found a competitive mode of inhibition for the above FQs except CPFX which was non-competitive manner. These results are consisted for CPFX but no other FQs. This could be due to species variation and inhibitors specificity in the two different species (Cats and dogs). The $\mathrm{K}_{\mathrm{i}}$ values of CPFX for cats and dogs were approximately similar (0.74 and 0.70 $\mathrm{mM}$ ) but in case of other FQs inhibitory effects were potent than those in dogs as described above. These values suggest that the inhibitory effects on CYP $1 \mathrm{~A}$ of cats are quite small than dogs. In contrast, NFX and CPFX in cats and, OFX, and ORBFX showed time-dependent inhibition in dogs, respectively. Although it was not reported that CPFX and OFX could have time-dependent inhibition in humans, and OFX inhibits CYP1A activities by this manner in hepatic microsomes obtained from humans [35].

Theophylline a substrate of CYP1A showed drug-drug interaction with FQs in dogs. This result was reported by Intorre et al. (1995), after they examined intravenous injection of ENFX on steady state levels of theophylline following oral administration in dogs [34]. They instituted rises in the steady state blood theophylline meditations; because of ENFX treatment. This could be inferred from the time-dependent inhibition of ENFX metabolite, CPFX. As we know ENFX biotransformed in the liver to CPFX and itself does not have this kind of inhibitory method, it is therefore, reversible inhibition is relatively small [13]. Even though OFX displays the method of time-dependent inhibition, but it does not affect theophylline pharmacokinetics in dogs [28]. Moreover, it has been reported that levofloxacin does not affect theophylline pharmacokinetics in humans [36], while some FQs would affect.

Several FQs (CPFX, OBFX, NFX, OFX and EFX) have inhibited both MDZ1 hydroxylation and MDZ4 hydroxylation catalyzed by CYP3A in a noncompetitive mode in cats. As of FQs, $K_{i}$ values were relatively large, and similar to those for EROD catalyzed by CYP1A. Therefore, the values were too large to elicit substantial inhibition in feline patients by reversible manner. In contrast, CPFX inhibited the reactions by irreversible manner, (time-dependent). Consequently, drug-drug interaction enabled by enzyme inhibition rises accumulation of medicines, current inhibitors could effect in deadly adversarial properties of concomitant drugs. It is, therefore, commonly accepted that ample consideration 
should be fulfilled to that nature of interaction [7].

As we know multiple drug therapy is also common in treatment of small animals like cats and dogs. It is, therefore, much more care must be paid to possible risk of interaction. However, CPFX may have a possibility of substantial inhibitory effect on CYP3A in feline patients. In the case of EFX same incidence will happen as mentioned above.

Numerous studies reported inhibitory effects of FQs on CYP3A activities in humans [8] [10], rats [10], and chickens [37]. EFX, CPFX, OFX, NFX, and ORBFX, however, did not affect Michaelis-Menten kinetics of 1'-hydroxylation of midazolam with dog hepatic microsomes. As well, EFX and OFX did not affect the pharmacokinetics of a CYP3A substrate, quinidine, by subsequent intravenous injection in dogs [9]. In this study we examined the effects in cats, the outcomes were nearly the same as described in dogs [9]. Therefore, FQs may not be responsible for a CYP3A mediated drug-drug interaction in dogs and cats by reversible manner.

The authors acknowledge limitations due to the time and space in our laboratory, we only used limited number of animals in this study. Therefore, further studies are needed to establish whether FQs express inhibitory effects by in vivo, and whether the inhibitory effects results from all the above drugs in cats similarly.

\section{Conclusion}

Several FQs inhibited CYP1A and CYP3A activities in hepatic microsomes of cats by a competitive or a noncompetitive manner with relatively large $K_{i}$ values. Hence, reversible inhibition effects may not be significant in clinical conditions, because $K_{i}$ values were quite large. Results also indicated that some of the FQs inhibited the activities of CYP1A and CYP3A by irreversible manner. While the inhibitory effects based on time-dependent inhibition is cumulative, it is therefore might cause drug instruction. This proposes that repeatedly administration drugs such as NFX and CPFX or EFX may inhibit CYP1A and CYP3A actions to produce inhibition-based drug interface in feline species. Consequently, clinicians should be more alert in feline clinics, when concurrently use FQs that is not approved for cats with extra drugs that are mostly removed by biotransformation of CYP1A and CYP3A subfamilies, such as THP and Quinidine. Further study is required in next future to elucidate the situation of FQs clearly.

\section{Acknowledgements}

This research was supported by Department of Veterinary Medicine, Faculty of Agriculture, Tokyo University of Agriculture and Technology, Japan government.

\section{Conflicts of Interest}

The authors declare no conflicts of interest regarding the publication of this paper. 


\section{References}

[1] Hojo, T., Ohno, R., Shimoda, M. and Kokue, E. (2002) Enzyme and Plasma Protein Induction by Multiple Oral Administrations of Phenobarbital at a Therapeutic Dosing Regimen in Dogs. Journal of Veterinary Pharmacology and Therapeutics, 25, 121-127. https://doi.org/10.1046/j.1365-2885.2002.00385.x

[2] Kuroha, M., Kuze, M.Y., Shimoda, M. and Kokue, E. (2002) In vitro Characterization of the Inhibitory Effects of Ketoconazole on Metabolic Activities of Cytochrome P-450 in Canine Hepatic Microsomes. American Journal of Veterinary Research, 63, 900-905. https://doi.org/10.2460/ajvr.2002.63.900

[3] Huang, S.M., Lesko, I.J. and Williams, R. L. (1999) Assessment of the Quality and Quantity of Drug-Drug Interaction Studies in Recent NDA Submissions: Study Design and Data Analysis Issues. The Journal of Clinical Pharmacology, 39, 1006-1014. https://doi.org/10.1177/00912709922011764

[4] Huang, S.M. and Lesko, I.J. (2004) Drug-Drug, Drug-Dietary Supplement and Drug-Citrus Fruit and Other Food Interactions: What Have We Learned? The Journal of Clinical Pharmacology, 44, 559-569.

https://doi.org/10.1177/0091270004265367

[5] Dresser, G.K., Spence, J.D. and Bailey, D.G. (2000) Pharmacokinetic Pharmacodynamics Consequences and Clinical Relevance of Cytochrome P450 3A4 Inhibition. Clinical Pharmacokinetics, 38, 41-57. https://doi.org/10.2165/00003088-200038010-00003

[6] Pea, F. and Furlanut, M. (2001) Pharmacokinetic Aspect of Treating Infections in the Intensive Care Unit: Focus on Drug Interactions. Clinical Pharmacokinetics, 40, 833-868. https://doi.org/10.2165/00003088-200140110-00004

[7] Shimoda, M. and Sasaki, K. (2015) Possible Drug-Drug Interaction in Dogs and Cats Resulted from Alteration in Drug Metabolism, a Mini Review. Journal of Advanced Research, 6, 382-392.

[8] Brouwers, E.E., Söhne, M., Kuipers, S., van Gor, E.C., Schellen, J.H., Koks C.H., et al, (2009) Ciprofloxacin Strongly Inhibits Clozapine Metabolism: Two Case Reports. Clinical Drug Investigation, 29, 59-63. https://doi.org/10.2165/0044011-200929010-00006

[9] Regmi, N.L., Abdel-Aty, A.M., Kubota, R., Shah, S.S. and Shimoda, M. (2007) Lack of Inhibitory Effects of Several Fluoroquinolones on Cytochrome P-450 3A Activities at Clinical Dosage in Dogs. Journal of Veterinary Pharmacology and Therapeutics, 30, 37-42. https://doi.org/10.1111/j.1365-2885.2007.00810.x

[10] McLellan, R.A., Drobitch, R.K., Monshouwer, M. and Renton, K.W. (1996) Fluoroquinolone Antibiotics Inhibit Cytochrome P-Mediated Microsomal Drug Metabolism in Rat and Human. Drug Metabolism \& Disposition, 24, 1134-1138.

[11] Wetzstein, H.G. and de Jong, A. (1996) In Vitro Bactericidal Activity and Post Antibiotic Effect of Fluoroquinolones Used in Veterinary Medicine. Compendium on Continuing Education for the Practicing Veterinarian, 18, 22-29.

[12] Shou, M., Norcross, R., Sandig, G., et al. (2003) Substrate Specificity and Kinetic Properties of Seven Heterologously Expressed Dog Cytochromes P450. Drug Metabolism \& Disposition, 31, 1161-1169. https://doi.org/10.1124/dmd.31.9.1161

[13] Regmi, N.L., Abd el-Aty, A.M., Kuroha, R.M., Nakamura, M. and Shimoda, M. (2005) Inhibitory Effect of Several Fluoroquinolones on Hepatic Microsomal Cytochrome P-450 1A Activities in Dogs. Journal of Veterinary Pharmacology and Therapeutics, 28, 553-557. https://doi.org/10.1111/j.1365-2885.2005.00698.x 
[14] Rendic, S. and Di Carlo, F. J. (1997) Human Cytochrome P450 Enzymes: A Status Report Summarizing Their Reactions, Substrates, Inducers, and Inhibitors. Drug Metabolism Reviews, 29, 413-580. https://doi.org/10.3109/03602539709037591

[15] Richez, P., Monolouis, J.D., Dellac, B. and Daube, B. (1997) Validation of a Therapeutic Regimen for Enerofloxacin in Cats on the Basis of Pharmacokinetic Data. Journal of Veterinary Pharmacology and Therapeutics, 20, 152-153.

[16] Sarkar, M., Polk, R.E., Guzelian, P.S., Hunt, C. and Karnes, H.T. (1990) In Vitro Effect of Fluoroquinolones on Theophylline Metabolism in Human Liver Microsomes. Antimicrobial Agents and Chemotherapy, 34, 594-599. https://doi.org/10.1128/AAC.34.4.594

[17] Rando, R.R. (1977) Mechanism-Based Irreversible Enzyme Inhibitors. Methods in Enzymology, 46, 28-41. https://doi.org/10.1016/S0076-6879(77)46007-5

[18] Shah, S.S., Sasak, K., Hayashi, Y., Motoyama, S., Helmi, A.R. and Khalil, W.F. (2009) Inhibitory Effects of Ketoconazole, Cimetidine and Erythromycin on Hepatic CYP3A Activities in Cats. The Journal of Veterinary Medical Science, 71, 115-119. https://doi.org/10.1292/jvms.71.1151

[19] Vaccaro, E., Giorgi, M., Longo, V., Mengozzi, G. and Gervasi, P.G. (2003) Inhibion of Cytochrome P450 Enzymes by Enerofloxacin in the Sea Bass (Dicentrarchus labrax). Aquatic Toxicology, 62, 27-33. https://doi.org/10.1016/S0166-445X(02)00064-4

[20] Davis, J.D., Aarons, L. and Houston, J. B. (1995) Effect of Norfloxacin on Theophylline Disposition: A Comparison with Other Fluoroquinolones. Pharmaceutical Research, 12, 257-262. https://doi.org/10.1023/A:1016287128048

[21] Palfreyman, M.G., Bey, P. and Sjoerdsma, A. (1987) Enzyme-Activated/MechanismBased Inhibitors. Essays in Biochemistry, 23, 28-81.

[22] Bradford, M.M. (1976) A Rapid and Sensitive Method for the Quantitation of microgram Quantities of Protein Utilizing the Principle of Protein-Dye Binding. Analytical Biochemistry, 72, 248-254. https://doi.org/10.1016/0003-2697(76)90527-3

[23] Omura, T. and Sato, R. (1964) The Carbon Monoxide Binding Pigment of Liver Microsomes. Journal of Biological Chemistry, 239, 2370-2378.

[24] Burke, M.D., Prough, R.A. and Mayer, R.T. (1977) Characteristics of a Microsomal Cytochrome P-448-Mediated Reaction, Ethoxyresorufin O-Deethylation. Drug Metabolism and Disposition, 5, 1-8.

[25] Burke, M.D., Prough, R.A. and Mayer, R.T. (1994) Cytochrome P450 Specificities of Alkoxyresorufin O-Dealkylation in Human and Rat Liver. Biochemistry Pharmacology, 48, 923-936. https://doi.org/10.1016/0006-2952(94)90363-8

[26] Kuroha, M., Azumano, A. Kuze, Y., Shimoda, M. and Kokue, E. (2002) Effect of Multiple Dosing of Ketoconazole on Pharmacokinetics of Midazolam, a Cytochrome P-450 3A Substrate in Beagle Dogs. Drug Metabolism and Disposition, 30 63-68. https://doi.org/10.1124/dmd.30.1.63

[27] Yamaoka, K., Tanigawara, Y., Nakagawa, T. and Uno, T.A. (1981) Pharmacokinetic Analysis Program (MULTI) for Microcomputer. Journal of Pharmacobio-Dynamics, 4, 879-885. https://doi.org/10.1248/bpb1978.4.879

[28] Regmi, N.L., Abd El-Aty, A.M., Kubota, R., Tomita, A. and Shimoda, M. (2006) Effect of Ofloxacin on Theophylline Pharmacokinetics at Clinical Dosage in Dogs. Journal of Veterinary Pharmacology and Therapeutics, 29, 403-408. https://doi.org/10.1111/j.1365-2885.2006.00784.x 
[29] Albarellos, G.A., Kreil, V.E. and Landoni, M.F. (2004) Pharmacokinetics of Ciprofloxacin after Single Intravenous and Repeat Oral Administration to Cats. Journal of Veterinary Pharmacology and Therapeutics, 27, 155-162. https://doi.org/10.1111/j.1365-2885.2004.00573.x

[30] Beckman, J., Elsässer, W., Gundert-Remy, U. and Hertrampf, R. (1987) Enoxan-A Potent Inhibitor of Theophylline Metabolism. European Journal of Clinical Pharmacology, 33, 227-230. https://doi.org/10.1007/BF00637553

[31] Wijnands, W.J.A., Van Herwaarden, C.L.A. and Vree, T.B. (1984) Enoxacin Raises Plasma Theophylline Concentrations. The Lancet, 324, 108-109. https://doi.org/10.1016/S0140-6736(84)90283-6

[32] Gregoire, S.L., Grasela, T.H., Freer, J.P., Tack, K.J. and Schentage, J.J. (1987) Inhibition of Theophylline Clearance by Co-Administered Ofloxacin without Alteration of Theophylline Effects. Antimicrobial Agents and Chemotherapy, 31, 375-378. https://doi.org/10.1128/AAC.31.3.375

[33] Niki, Y., Soejima, R., Kawane, H., Sumi, M. and Umeki, S. (1987) New Synthetic Quinolone Antimicrobial Agents and Serum Concentration of Theophylline. Chest, 92, 663-669. https://doi.org/10.1378/chest.92.4.663

[34] Intorre, L., Mengozzi, G., Maccheroni, M., Bertini, S. and Soldani, G. (1995) Enerofloxacin-Theophylline Interaction: Influence of Enerofloxacin on Theophylline Steady-State Pharmacokinetics in the Beagle Dog. Journal of Veterinary Pharmacology and Therapeutics, 18, 352-356. https://doi.org/10.1111/j.1365-2885.1995.tb00603.x

[35] Pan, X., Wang, P., Hu, N., Liu, L., Liu, X., Xie, L. and Wang, G. (2011) A Physiologically Based Pharmacokinetic Model Characterizing Mechanism-Based Inhibition of CYP1A2 for Predicting Theophylline/Antofloxacin Interaction in Both Rats and Humans. Drug Metabolism and Pharmacokinetics, 26, 387-398. https://doi.org/10.2133/dmpk.DMPK-10-RG-126

[36] Gisclon, G.L., Curtin, C.R., Fowler, C.L., Williams, R.R., Hafkin, B. and Natarajan, J. (1997) Absence of a Pharmacokinetic Interaction between Intravenous Theophylline and Orally Administered Levofloxacin. The Journal of Clinical Pharmacology, 37, 744-775. https://doi.org/10.1002/j.1552-4604.1997.tb04362.x

[37] Hu, H.F., Gao, Z.X. and Cheng, Y.Y. (2010) Inhibition of CYP3A mRNA and Exprezassion, and Enzymatic Activity, by Enerofloxacin in Chickens. Journal of Veterinary Pharmacology and Therapeutics, 33, 546-550.

https://doi.org/10.1111/j.1365-2885.2010.01175.x 